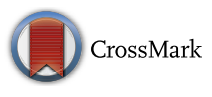

Cite as

Nano-Micro Lett.

(2019) 11:9

Received: 15 November 2018

Accepted: 2 January 2019

Published online: 22 January 2019

(C) The Author(s) 2019

\section{N, F-Codoped Microporous Carbon Nanofibers as Efficient Metal-Free Electrocatalysts for ORR}

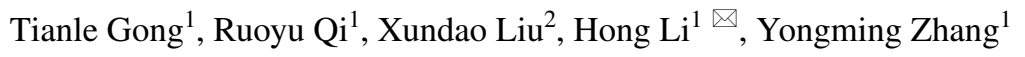 \\ $\square$ Hong Li, 1h102@sjtu.edu.cn \\ 1 Shanghai Electrochemical Energy Devices Research Center, Shanghai Key Lab of Electrical Insulation \\ and Thermal Aging, School of Chemistry and Chemical Engineering, Shanghai Jiao Tong University, \\ Shanghai 200240, People's Republic of China \\ 2 School of Material Science and Engineering, University of Jinan, Jinan 250022, People's Republic of China
}

\title{
HIGHLIGHTS
}

- A new and facile method to synthesize N, F-codoped microporous carbon nanofiber (N, F-MCF) electrocatalysts via electrospinning, hydrothermal process, and thermal treatment.

- Polyvinylidene fluoride is applied as a fluorine source in oxygen reduction reaction (ORR) catalysis for the first time in literature.

- N, F-MCFs exhibit distinguished electrocatalytic activity, stability, and methanol tolerance for ORR in alkaline media.

\begin{abstract}
Currently, the oxygen reduction reaction (ORR) mainly depends on precious metal platinum $(\mathrm{Pt})$ catalysts. However, Pt-based catalysts have several shortcomings, such as high cost, scarcity, and poor long-term stability. Therefore, development of efficient metal-free electrocatalysts to replace Pt-based electrocatalysts is important. In this study, we successfully prepared nitrogen- and fluorinecodoped microporous carbon nanofibers (N, F-MCFs) via electrospinning polyacrylonitrile/ polyvinylidene fluoride/polyvinylpyrrolidone (PAN/PVDF/PVP) tricomponent polymers followed by a hydrothermal process and thermal

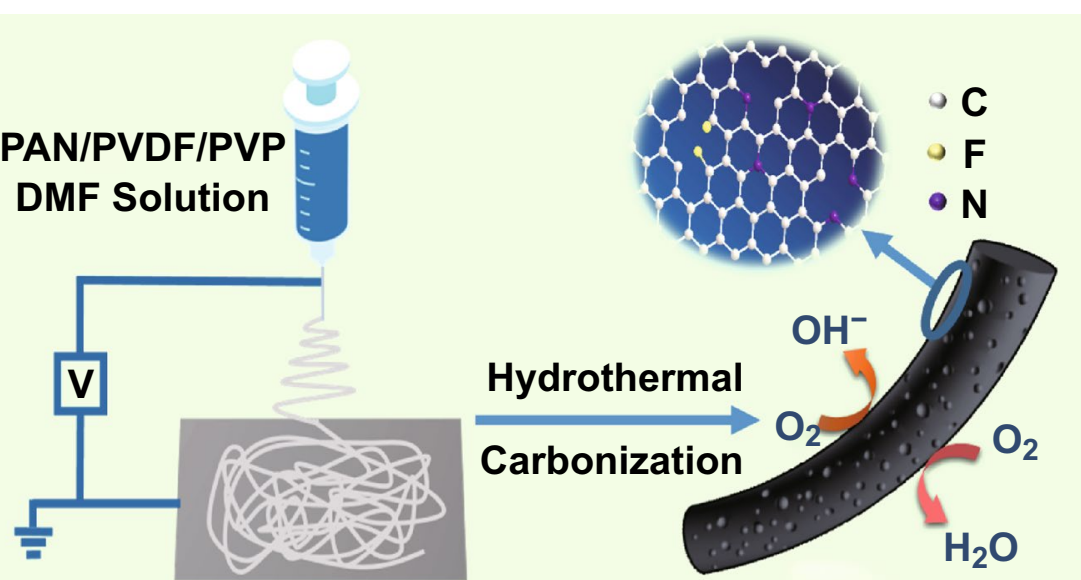

N, F-MCFs treatment, which was achieved for the first time in the literature. The results indicated that $\mathrm{N}, \mathrm{F}-\mathrm{MCF}$ exhibit a high catalytic activity $\left(E_{\text {onset }}: 0.94 \mathrm{~V}\right.$ vs. RHE, $E_{1 / 2}: 0.81 \mathrm{~V}$ vs. RHE, and electron transfer number: 4.0) and considerably better stability and methanol tolerance for ORR in alkaline solutions as compared to commercial Pt/carbon (Pt/C, $20 \mathrm{wt} \%$ ) catalysts. Furthermore, in acidic media, N, F-MCFs showed a four-electron transfer pathway for ORR. This study provides a new strategy for in situ synthesis of N, F-MCFs as highly efficient metal-free electrocatalysts for ORR in fuel cells.
\end{abstract}

KEYWORDS Metal-free catalyst; Oxygen reduction reaction; N, F-codoped; Carbon nanofiber; Polyvinylidene fluoride 


\section{Introduction}

Oxygen reduction reaction (ORR) electrocatalysts for proton exchange membrane fuel cells (PEMFCs) have gained significant attention because of their sluggish kinetic process [1-5]. To date, platinum $(\mathrm{Pt})$-loaded carbon is considered as the most effective ORR electrocatalyst [6-9]. However, Pt-based catalysts still have several shortcomings, such as poor durability, limited reserves, high cost, and carbon monoxide $(\mathrm{CO})$ poisoning $[10,11]$. Currently, metal-free heteroatom-doped carbons are widely considered as promising catalysts to replace Pt-based carbon catalysts in the near future because of their high electrocatalytic activity toward ORR, cost effectiveness, longterm cycling stability, and excellent tolerance to methanol and $\mathrm{CO}$ oxidations $[12,13]$. Among these materials, nitrogen $(\mathrm{N})$-doped carbons are extensively studied because the electronegativity of $\mathrm{N}$ (3.04) induces charge redistribution of adjacent atoms in an $\mathrm{N}$-doped carbon surface layer, which greatly enhances the ORR activity of carbon electrocatalysts [14-18]. Besides N, other nonmetal atoms with different electronegativities, such as boron (B) [19, 20], sulfur (S) [21, 22], phosphorus (P) [23, 24], and fluorine (F) [25-29], can enhance the ORR activity of carbon catalysts.

In addition, the largest electronegativity is observed in $\mathrm{F}$ atoms (4.0). Ishizaki et al. reported that $\mathrm{F}$ atoms bonded to ionic and semi-ionic $\mathrm{C}$ atoms can act as electron acceptors, which promote charge transfer between the $\mathrm{F}$ and $\mathrm{C}$ atoms, thereby resulting in higher conductivity and modification of the electronic properties of pristine carbons [30]. Moreover, $\mathrm{Lu}$ et al. reported that $\mathrm{F}$ doping can improve the wettability of the catalyst surface, thereby facilitating both electrolyte and $\mathrm{O}_{2}$ transportation within porous frameworks [31]. Therefore, $\mathrm{F}$ doping is advantageous for ORR activities. Moreover, $\mathrm{N}$ and $\mathrm{F}$ atoms can enhance ORR activities by a synergetic effect. N, F-codoped carbon electrocatalysts, such as carbon black [25], mesoporous carbon [26, 32], graphdiyne [33], porous carbon [34], carbon nanoparticles [30], graphene [35], and graphite nanofibers [27], are widely prepared, and they exhibited excellent properties as ORR electrocatalysts in alkaline media. It is difficult to dope $\mathrm{F}$ atoms into carbon matrix; thus, a large number of $\mathrm{F}$ sources are required. Currently, $\mathrm{NH}_{4} \mathrm{~F}$ is the most commonly used $\mathrm{F}$ source. However, the facile decomposition property of $\mathrm{NH}_{4} \mathrm{~F}$ increases the synthesis difficulty of F-doped carbons. Further, the F-doped content in obtained carbon samples is less than 1 at $\%$, while the mass amount of $\mathrm{NH}_{4} \mathrm{~F}$ used is 20 times more than that of the carbon source $[25,27,33]$. Thus, it is important to develop new F sources and highly efficient F-doping methods.

Besides heteroatom doping, carbon morphology is another key factor that affects catalyst activities. High surface areas along with suitable micropores or mesopores can increase the number of active sites for ORR and facilitate $\mathrm{O}_{2}$ transportation during ORR. In this study, we present a facile in situ method to synthesize N, F-codoped microporous carbon nanofibers (N, F-MCFs) as electrocatalysts with high Brunauer-Emmett-Teller (BET) surface area via electrospinning polyacrylonitrile/ polyvinylidene fluoride/polyvinylpyrrolidone (PAN/ $\mathrm{PVDF} / \mathrm{PVP}$ ) tricomponent polymers followed by a hydrothermal process and thermal treatment. PVDF is used as a source of $\mathrm{F}$ and $\mathrm{C}$ atoms. PAN acts as a source of $\mathrm{N}$ and $\mathrm{C}$ atoms. PVP, which is removed by the hydrothermal process, is applied as a porogen for N, F-MCFs. The as-synthesized N, F-MCFs are characterized systematically, and their ORR activities and stabilities are investigated. Benefitted from the N, F-codoped effect and unique nanofiber structure with microporous pore walls, N, F-MCFs exhibit both highly catalytic activity and stabilities for ORR in alkaline solutions. The catalytic activity of N, F-MCFs in acidic solutions is also investigated preliminarily.

\section{Experimental Methods}

\subsection{Materials and Chemicals}

PAN $\left(M_{\mathrm{w}}=150,000 \quad \mathrm{~g} \mathrm{~mol}^{-1}\right)$ and PVP $\left(M_{\mathrm{w}}=10,000 \mathrm{~g} \mathrm{~mol}^{-1}\right)$ were purchased from J\&K Scientific Ltd. PVDF (Solef 5130) was obtained from Solvay. $5 \%$ Nafion $^{\circledR}$ solution (Nafion 117) was obtained from E. I. DuPont Company. Other chemicals, such as $\mathrm{N}, \mathrm{N}$-dimethylformamide (DMF), potassium hydroxide (KOH), and ethanol, were purchased from Sinopharm Chemical Reagent CO., Ltd. and used as received. Deionized water was used throughout the experiments. 


\subsection{Electrospinning of PAN/PVP/PVDF Membranes}

The tricomponent PAN/PVP/PVDF nanofibrous membranes were prepared via facile single-nozzle electrospinning. The PAN (3wt\%), PVP (3wt\%), and PVDF (3 wt \%) membranes were mixed in a sealed glass bottle with DMF and magnetically stirred for $24 \mathrm{~h}$ at room temperature as a precursor solution. Further, this precursor solution was loaded into a 3-mL plastic syringe connected with a stainless needle of $0.5 \mathrm{~mm}$ inner diameter. During the electrospinning process, the operating voltages were $12 \mathrm{kV}$, the flow rate was $0.2 \mathrm{~mL} \mathrm{~h}^{-1}$, and the collecting distance was $14 \mathrm{~cm}$. The electrospun PAN/PVP/PVDF membranes were peeled off from the aluminum foil.

\subsection{Preparation of N, F-MCFs}

The electrospun PAN/PVP/PVDF membranes were transferred into a $100-\mathrm{mL}$ Teflon stainless autoclave with deionized water and hydrothermally treated under $110{ }^{\circ} \mathrm{C}$ for $6 \mathrm{~h}$ to remove PVP. Further, the hydrothermal-treated membranes were washed with deionized water and dried under $100^{\circ} \mathrm{C}$ in a blast oven to obtain PAN/PVDF fibrous membranes.

The peroxidation and carbonization of these PAN/PVDF fibers were performed in an electric heating tube furnace. First, the dried PAN/PVDF fibrous membranes were sealed in a graphite boat covered by a carbon paper. Subsequently, the samples were preoxidized in an air atmosphere under $220{ }^{\circ} \mathrm{C}$ for $2 \mathrm{~h}$ at a heating rate of $2{ }^{\circ} \mathrm{C} \mathrm{min}-1$. Further, the samples were carbonized in an $\mathrm{N}$ atmosphere under $1000{ }^{\circ} \mathrm{C}$ for $2 \mathrm{~h}$ at a heating rate of $2{ }^{\circ} \mathrm{C} \mathrm{min}^{-1}$. The asprepared samples (N, F-MCFs) were cooled down to the room temperature.

\subsection{Physical and Electrochemical Characterization}

The morphology of N, F-MCFs was characterized by transmission electron microscopy (TEM) and scanning electron microscopy (SEM) using Nova NanoSEM 450 and Talos F200X (both from FEI Company, USA), respectively. X-ray photoelectron spectroscopy (XPS, K $\alpha$ ) analyses were performed on an AXIS UltraDLD X-ray photoelectron spectrometer system equipped with $\mathrm{Al}$ radiation as a probe, and the analysis spot size was $400 \mu \mathrm{m}$ in diameter. Raman spectra were collected by DXR Micro-Raman Spectroscopy (Thermo Fisher Scientific, USA), equipped with a holographic grating of 1800 lines $\mathrm{mm}^{-1}$ and a He-Ne laser $(532 \mathrm{~nm})$ as the excitation source. BET measurements were performed on an ASAP 2460 surface area and porosimetry analyzer (Micromeritics Instrument Corp., USA).

All electrochemical measurements were performed on an Autolab PGSTAT302 (Metrohm, Netherlands) electrochemical workstation with a standard three-electrode system. A glassy carbon electrode, $\mathrm{Ag} / \mathrm{AgCl}$, and $\mathrm{Pt}$ wire were used as the working, reference, and counter electrodes, respectively. The catalyst ink consisted of 1-mg sample, $8 \mu \mathrm{L} 5 \%$ Nafion 117 solution, ethanol, and water suspension. After ultrasonic homogenization, the ink was coated on a glassy carbon electrode (working electrode), which led to a catalyst loading of about $0.3 \mathrm{mg} \mathrm{cm}^{-2}$ for all working electrodes. Linear sweep voltammetry (LSV) measurement was performed by glassy carbon rotating disk electrode (RDE) cathodically scanned with varying rotating speed from 400 to $2000 \mathrm{rpm}$ at a rate of $5 \mathrm{mV} \mathrm{s}^{-1}$. The electron transfer number per $\mathrm{O}_{2}$ during the ORR process was calculated by the LSV curves and Koutecky-Levich (K-L) equations (Eqs. 1-3)

$\frac{1}{J}=\frac{1}{J_{\mathrm{L}}}+\frac{1}{J_{\mathrm{K}}}=\frac{1}{B \omega^{1 / 2}}+\frac{1}{J_{\mathrm{K}}}$

$B=0.62 n F D_{\mathrm{O}_{2}}^{2 / 3} C_{\mathrm{O}_{2}}^{\mathrm{b}} v^{-1 / 6}$

$\left|J_{\mathrm{k}}\right|=n F k_{\mathrm{f}} C_{\mathrm{O}_{2}}^{\mathrm{b}}$

where $J$ is the measured current density, $J_{\mathrm{K}}$ and $J_{\mathrm{L}}$ are the kinetic and diffusion-limiting current densities, respectively, $\omega$ is the angular velocity $\left(\mathrm{rad} \mathrm{s}^{-1}\right), F$ is the Faraday constant $\left(96,485 \mathrm{C} \mathrm{mol}^{-1}\right), n$ is the transfer electron number, $C_{\mathrm{O}}^{\mathrm{b}}$ is the bulk concentration of $\mathrm{O}_{2}\left(1.2 \times 10^{-3} \mathrm{~mol} \mathrm{~cm}^{-3}\right), D_{\mathrm{O}_{2}}^{2 / 3}$ is the diffusion coefficient of $\mathrm{O}_{2}$ in the electrolyte $\left(1.9 \times 10^{-5}\right)$, $v$ is the kinematic viscosity of the electrolyte $\left(0.01 \mathrm{~cm}^{2} \mathrm{~s}^{-1}\right)$, and $k_{\mathrm{f}}$ is the electron transfer rate constant.

\section{Results and Discussion}

\subsection{Structure and Morphology of N, F-MCFs}

The overall preparation process for N, F-MCFs is illustrated in Scheme 1. As shown in Scheme 1, the PAN/PVP/PVDF 


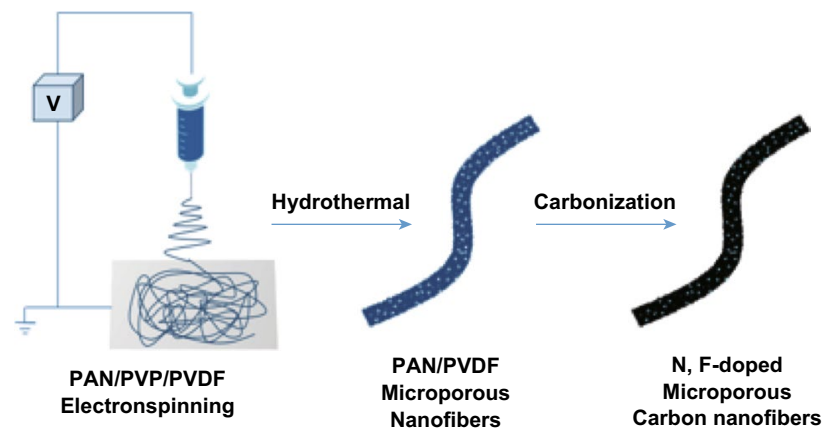

Scheme 1 Schematic illustration of N, F-MCFs ORR catalysts

tricomponent nanofibers are first obtained by electrospinning a mixture of PAN, PVP, and PVDF in the DMF solution. Further, they are hydrothermally treated under $110^{\circ} \mathrm{C}$ for $6 \mathrm{~h}$, and then preoxidized and carbonized at 220 and $1000{ }^{\circ} \mathrm{C}$, respectively, thereby resulting in N, F-MCFs. There are two mass ratios of PAN, PVP, and PVDF for the prepared N, F-MCFs, $1 / 1 / 1$ and 1/1/1.5, which are separately named as N, F-MCFs-A and N, F-MCFs-B, respectively. To investigate the effects of pores and $\mathrm{F}$ atoms on $\mathrm{N}, \mathrm{F}-\mathrm{MCFs}$, we synthesized N-MCFs-C without $\mathrm{F}$ atom doping from
PAN/PVP bicomponent polymers and N, F-CFs-D without micropores from PAN/PVDF bicomponent polymers for comparison.

The morphology of electrospun PAN/PVP/PVDF nanofibers for the entire preparation process was characterized by SEM. As shown in Fig. 1a, smooth and uniform electrospun PAN/PVP/PVDF nanofibers exhibited a mean diameter of about $180 \mathrm{~nm}$ with random orientation. After removing PVP of the hybrid fibers by hydrothermal treatment, the surface of the nanofibers becomes rough and uneven, as shown in Fig. 1b. We can observe that some pores appear on the fibers. However, the continuous and uniform fiber structure is maintained after the hydrothermal treatment as well. The heat treatment of the porous nanofibers includes two processes, pre-oxidation and carbonization. During pre-oxidation in air at $220^{\circ} \mathrm{C}$, PAN undergoes cyclization and partial dehydrogenation, which make fibers more stable during subsequent high-temperature carbonization and create more defects for doping heterogeneous atoms [36]. As shown in Fig. 1c, d, the obtained N, F-MCFs became thinner and denser after carbonization, and cracks formed on their surface. The nanofiber structure with pores and the amorphous
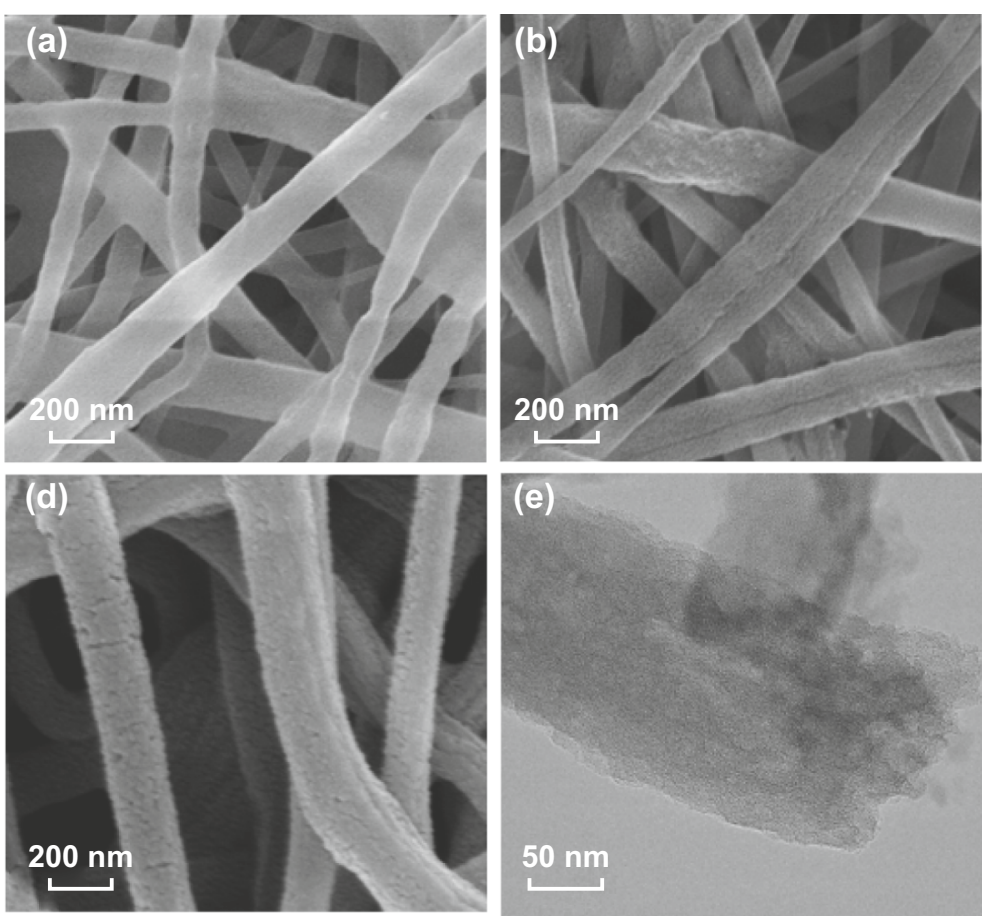
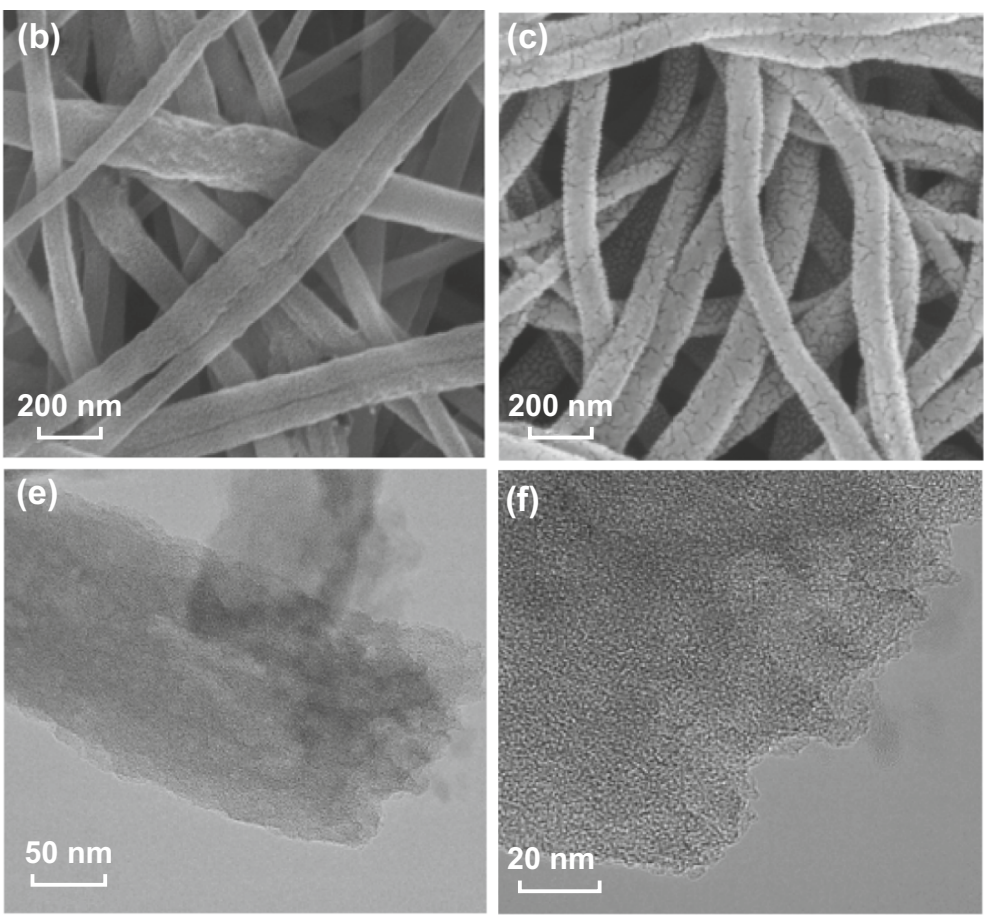

Fig. 1 SEM images of a electrospun PAN/PVP/PVDF nanofibers, b PAN/PVDF porous nanofibers after hydrothermal treatment, N, F-MCFs with different compositions, $\mathbf{c} \mathrm{PAN} / \mathrm{PVP} / \mathrm{PVDF}=1 / 1 / 1$, and $\mathbf{d} \mathrm{PAN} / \mathrm{PVP} / \mathrm{PVDF}=1 / 1 / 1.5$. e, $\mathbf{f}$ TEM images of $\mathrm{N}, \mathrm{F}-\mathrm{MCF}$ 
carbon microcrystalline structure can be observed in the TEM images of N, F-MCFs-A (Fig. 1e, f).

The crystal structure and degree of graphitization are further characterized by XRD analyses and Raman spectrum. Two broad peaks at around $2 \theta=25^{\circ}$ and $44^{\circ}$, corresponding to the (002) and (100) planes of carbon, respectively, validate the amorphous carbon structure in Fig. $2 a$. Figure $2 b$ shows three typical D, G, and 2D bands at about 1344, 1598, and $2798 \mathrm{~cm}^{-1}$, respectively. The D-band represents the defects and disordered structure of carbon lattice, while the G-band is a characteristic feature of in-plane vibration of $s p^{2}$ bonded carbon atoms, which indicates the ordered structure of the carbon materials. It is known that the ratio of D-band and G-band $\left(I_{\mathrm{D}} / I_{\mathrm{G}}\right)$ is attributed to determine the degree of graphitization or the defect density of carbon materials. The $I_{\mathrm{D}} / I_{\mathrm{G}}$ ratios of $\mathrm{N}$, F-MCFs-A and $\mathrm{N}$, F-MCFs-B are as high as 2.98 and 2.31 , respectively, which suggests that many defect sites and disordered structures are caused by doping $\mathrm{N}$ and $\mathrm{F}$ atoms. Moreover, they are in accordance with the broad peak of (002) obtained from the XRD results.

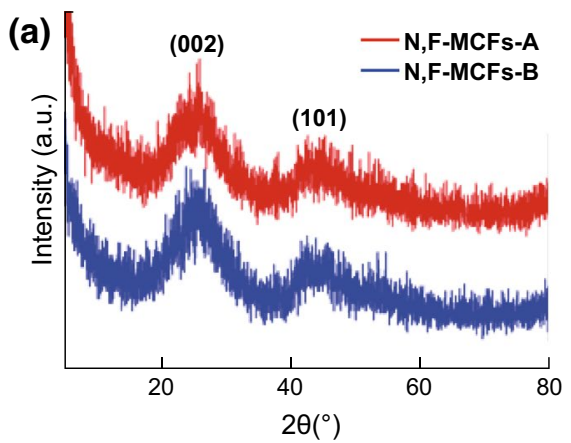

(c)

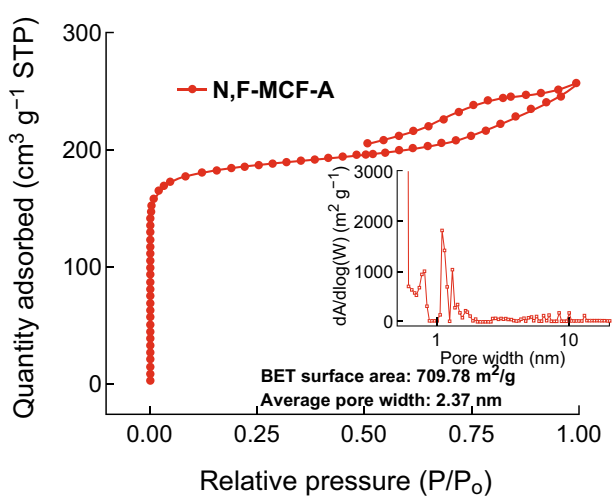

The pore structure of N, F-MCFs was investigated by adsorption-desorption isotherms of $\mathrm{N}_{2}$ at $-196{ }^{\circ} \mathrm{C}$. As shown in Fig. 2c, d, both isotherms are between type I isotherms with type $\mathrm{H} 4$ hysteresis loops following IUPAC classification, thereby indicating the existence of micropores. The BET surface areas of N, F-MCFs-A and N, F-MCFs-B are 709.78 and $621.46 \mathrm{~m}^{2} \mathrm{~g}^{-1}$, respectively. The corresponding pore size distributions of the two samples are calculated by Barrett-Joyner-Halenda (BJH) desorption, and their average pore widths are 2.37 and $2.77 \mathrm{~nm}$. The large BET surface area and the existence of micropores are advantageous for high ORR activities.

The elemental composition and the contents of $\mathrm{N}$ and $\mathrm{F}$ heteroatoms onto the catalysts surface were characterized by XPS measurements. The XPS survey spectra for N, F-MCFs-A and N, F-MCFs-B showed the existence of the $\mathrm{C} 1 \mathrm{~s}, \mathrm{O} 1 \mathrm{~s}, \mathrm{~N} 1 \mathrm{~s}$, and F 1s peaks. The XPS quantitative result demonstrated that the relative surface mass ratios of $\mathrm{C}, \mathrm{O}, \mathrm{N}$, and $\mathrm{F}$ are $89.01,6.12,2.06$, and $2.81 \%$ in $\mathrm{N}$, F-MCFs-A, and 87.48, 8.26, 1.79, and $2.48 \%$ in N, F-MCFs$\mathrm{B}$, respectively. The high-resolution $\mathrm{N}$ 1s spectrum can be

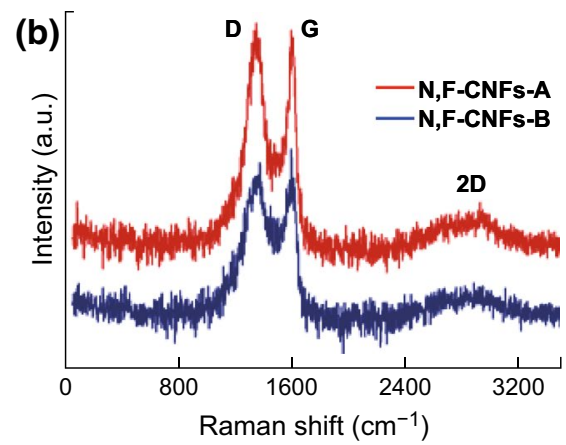

(d)

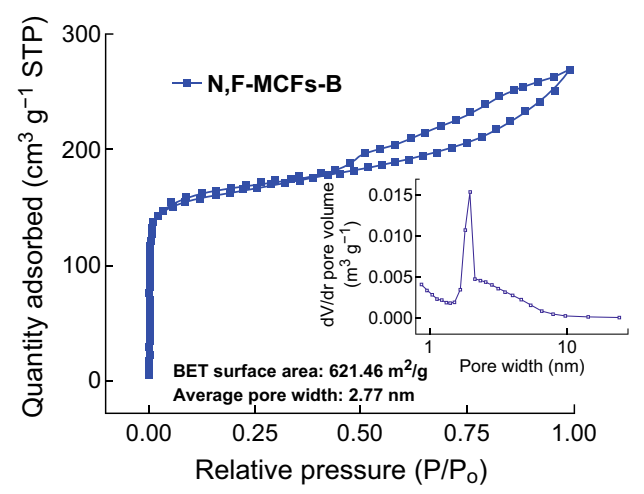

Fig. 2 a XRD patterns, b Raman spectra, $\mathbf{c}, \mathbf{d} \mathrm{N}_{2}$ adsorption isotherms (inset of $\mathbf{c}$ and $\mathbf{d}$ is pore size distributions of N, F-MCFs-A and N, F-MCFs-B) 
further deconvoluted into four peaks centered at $398.5 \pm 0.2$ $\mathrm{eV}, 400.1 \pm 0.2 \mathrm{eV}, 401.1 \pm 0.2 \mathrm{eV}$, and $404 \pm 0.2 \mathrm{eV}$, corresponding to pyridinic $\mathrm{N}$, pyrrolic $\mathrm{N}$, graphitic $\mathrm{N}$, and quaternary $\mathrm{N}$, respectively. The relative content of pyridinic $\mathrm{N}$ and graphitic $\mathrm{N}$ is much higher than that of pyrrolic $\mathrm{N}$ and quaternary $\mathrm{N}$, which may contribute to the high ORR activity of the catalyst $[26,27,34]$. The method of doping $F$ atoms via PVDF can obtain higher content $(>2 \%$ ) than those methods discussed in the earlier literature, which could be beneficial to the ORR electrocatalytic activity. The high-resolution $\mathrm{F} 1 \mathrm{~s}$ spectrum was usually deconvoluted into semi-ionic $\mathrm{F}$ $(688.8 \pm 0.2 \mathrm{eV})$ and ionic $\mathrm{F}(685.4 \pm 0.2 \mathrm{eV})$. These two peaks can be observed in the $\mathrm{F}$ 1s spectrum of N, F-MCFs-B in Fig. 3f, while the F 1s spectrum of N, F-MCFs-A can be deconvoluted into three peaks in Fig. 3e, which include ionic $\mathrm{F}(685.4 \pm 0.2 \mathrm{eV})$ and two kinds of semi-ionic $\mathrm{F}, \mathrm{CH}_{2}-\mathrm{CF}_{2}$ $(689 \pm 0.2 \mathrm{eV})$ and CHF-CHF $(687.2 \pm 0.2 \mathrm{eV})$. We compared the high-resolution $\mathrm{F}$ 1s spectrum of F-monodoped catalyst (prepared by PVDF carbon fibers catalysts) with $\mathrm{N}$, F-MCFs in Fig. S4. The binding energy of the semi-ionic F in F-doped catalysts is lower than that in N, F-codoped catalysts, and the ionic $\mathrm{F}$ content of F-monodoped catalyst is much lower than N, F-codoped catalysts, which are probably because of the synergistic interactions between the $\mathrm{F}$ and $\mathrm{N}$ atoms. It is observed that ionic $\mathrm{F}$ can result in higher electrical conductivity and modification of electronic structures of carbon frameworks. Compared to the mass ratio of ionic $\mathrm{F}$ in N, F-MCFs-B (7.18\%), the higher mass ratio of the ionic $\mathrm{F}$ in N, F-MCFs-A (14.83\%) can provide more active sites for ORR to enhance the activity of the catalysts.

\subsection{Electrocatalytic Activities Toward ORR of N, F-MCFs}

The electrocatalytic activities of N, F-MCFs were first evaluated by cyclic voltammetry (CV) measurements in $\mathrm{N}_{2}$ - and $\mathrm{O}_{2}$-saturated $0.1 \mathrm{M} \mathrm{KOH}$ solution. The $\mathrm{CV}$ curves of $\mathrm{N}$, F-MCFs-A and N, F-MCFs-B in $\mathrm{N}_{2}$ - and $\mathrm{O}_{2}$-saturated $0.1 \mathrm{M}$ $\mathrm{KOH}$ solution are shown in Fig. S1. Figure 4a shows that the CV curves of N, F-MCFs-A and N, F-MCFs-B present two peak potentials at 0.881 and $0.846 \mathrm{~V}$, respectively, which are higher than those of N-MCFs-C (prepared from PAN/ PVP bicomponent polymers, without F-doped atoms) and N, F-CFs-D (prepared from PAN/PVDF bicomponent polymers without micropores). The more positive peak potentials indicate that more active sites for ORR are created by the
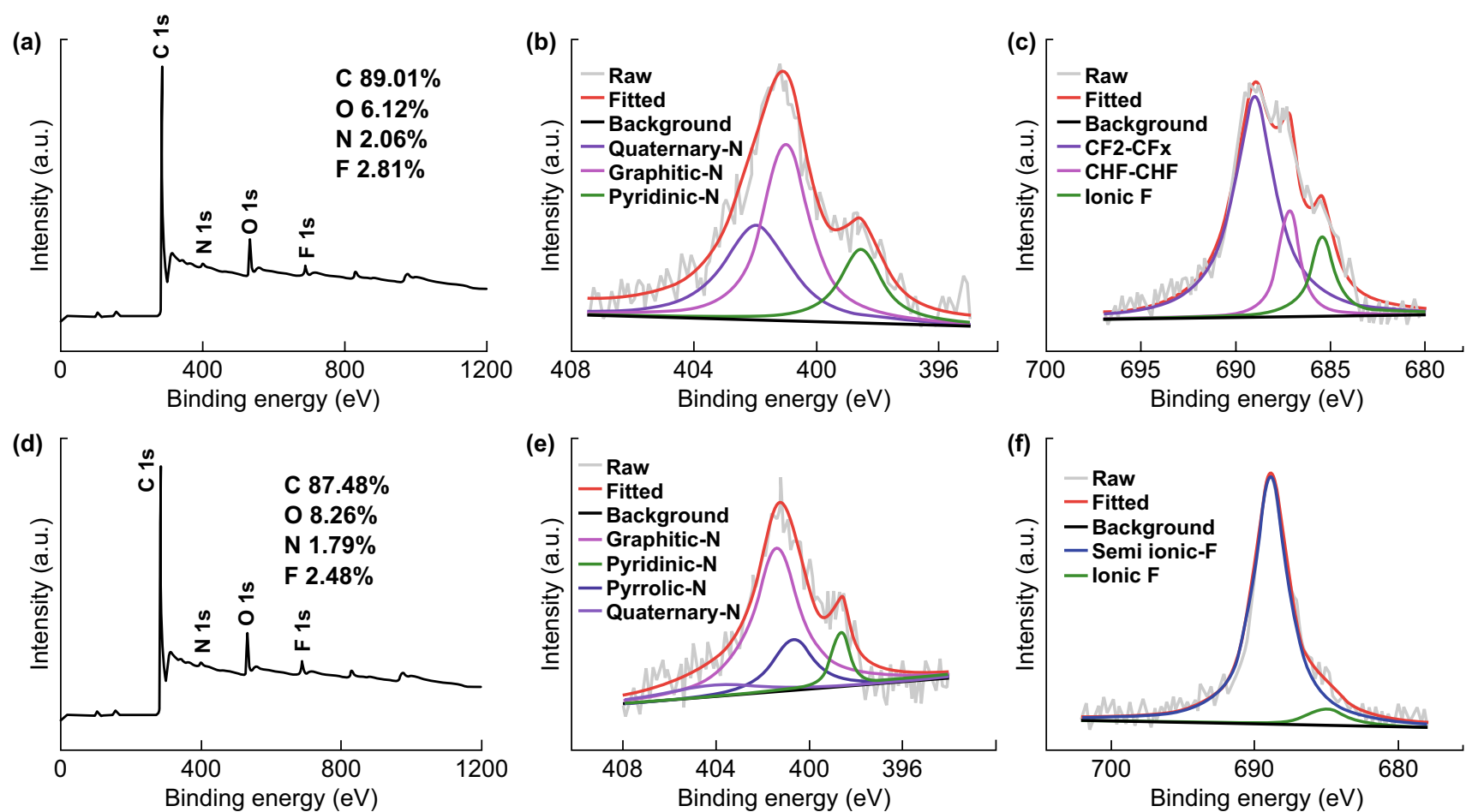

Fig. 3 a, $\mathbf{d}$ XPS spectra of N, F-MCFs-A and B. High-resolution XPS spectra of $\mathbf{b}, \mathbf{e} \mathrm{N}$ 1s and $\mathbf{c}, \mathbf{f}$ F $1 \mathrm{~s}$ of N, F-MCFs-A and B 

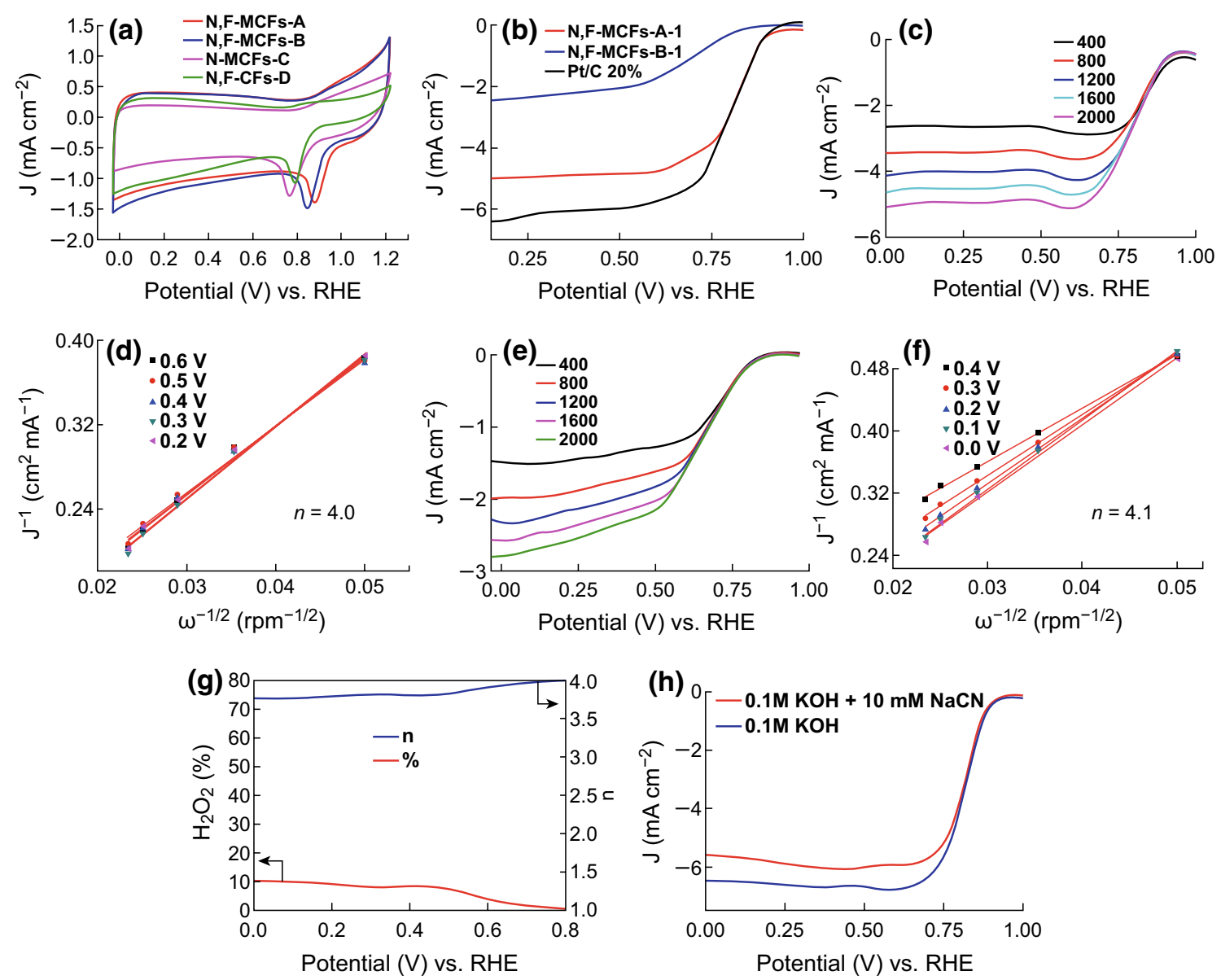

Fig. 4 a CV curves of N, F-MCFs-A; N, F-MCFs-B; N-MCFs-C; and N, F-CFs-D in $\mathrm{O}_{2}$-saturated $0.1 \mathrm{M} \mathrm{KOH}$ with a scan rate of $10 \mathrm{mV} \mathrm{s}^{-1}$. b LSV curves of N, F-MCFs-A; N, F-MCFs-B; and commercial 20\% Pt/C in $\mathrm{O}_{2}$-saturated $0.1 \mathrm{M} \mathrm{KOH}$ with a scan rate of $10 \mathrm{mV} \mathrm{s}^{-1}$. LSV curves and K-L plots of $\mathbf{c}, \mathbf{d}$ N, F-MCFs-A and e, $\mathbf{f} \mathrm{N}, \mathrm{F}-\mathrm{MCF}$-B. $\mathbf{g}$ Percentage of $\mathrm{H}_{2} \mathrm{O}_{2}$ yield and electron transfer number $(n)$ of N, F-MCFs-A. h LSV curves of N, F-MCFs-A with and without $10 \mathrm{mM} \mathrm{NaCN}$ in $\mathrm{O}_{2}$-saturated $0.1 \mathrm{M} \mathrm{KOH}$ with a scan rate of $10 \mathrm{mV} \mathrm{s}^{-1}$

high BET surface area and synergistic effect of the codoped heteroatoms. As shown in Fig. S2, the onset potential, halfwave potential, and limiting current density of N, F-MCFs-A are all higher than those of N-MCFs-C, which can also prove that $\mathrm{F}$ doping improves the ORR activity. To further investigate the high ORR catalytic activity of N, F-MCFs-A and N, F-MCFs-B, the linear sweep voltammetry (LSV) measurements were performed via a rotating disk electrode (RDE) in $\mathrm{O}_{2}$-saturated $0.1 \mathrm{M} \mathrm{KOH}$ solution. As depicted in Fig. 4b, N, F-MCFs-A present more positive onset potential $(0.94 \mathrm{~V}$ vs. RHE) than that of N, F-MCFs-B (0.87 V vs. RHE) and it is also more approaching to that of the commercial Pt/C ( $0.95 \mathrm{~V}$ vs. RHE) because of its larger BET surface area and more doped content of $\mathrm{N}$ and $\mathrm{F}$. The high ORR electrocatalytic activity of N, F-MCFs-A can also be gleaned from its higher half-wave potential ( $0.81 \mathrm{~V}$ vs. RHE) than that of $\mathrm{N}$, F-MCFs-B (0.71 V vs. RHE) and close to commercial Pt/C (JM20, 0.83 V vs. RHE). However, N, F-MCFs-A exhibit a lower limiting current density $\left(4.9 \mathrm{~mA} \mathrm{~cm}^{-2}\right)$ than $\mathrm{Pt} / \mathrm{C}$ $\left(6.1 \mathrm{~mA} \mathrm{~cm}^{-2}\right)$. In addition, because of concerning about the impact of glass corrosion [37], we measured the LSV curves of N, F-MCFs-A and Pt/C in $\mathrm{O}_{2}$-saturated $0.1 \mathrm{M} \mathrm{KOH}$ solution with Teflon container (Fig. S5) and confirmed that in the short test time poison of Pt/C catalyst by impurities released from the glass cell in alkaline medium should be very little and not detectable.

To further estimate the ORR reaction kinetics of $\mathrm{N}$, F-MCFs, a series of LSV tests were carried out with various rotation speeds from 400 to $2000 \mathrm{rpm}$ in an $\mathrm{O}_{2}$-saturated 0.1 M KOH electrolyte (Fig. 4c, e). On 
the basis of LSV curves at different rotations, the Koutecky-Levich plots and the electron transfer numbers $(n)$ for ORR were obtained from the $\mathrm{K}-\mathrm{L}$ equations. The great linearity and parallelism of the K-L plots (Fig. 4d, f) suggest a direct four-electron pathway for better ORR efficiency. The average $n$ value of $\mathrm{N}, \mathrm{F}-\mathrm{MCFs}-\mathrm{A}$ and $\mathrm{N}$, F-MCFs-B is 4.0 and 4.1, which suggested that the complete reduction of $\mathrm{O}_{2}$ to $\mathrm{OH}^{-}$over $\mathrm{N}, \mathrm{F}-\mathrm{MCF}$ by a fourelectron transfer process in $0.1 \mathrm{M} \mathrm{KOH}$. For further confirmation of $4 \mathrm{e}^{-}$selectivity, the yield of $\mathrm{H}_{2} \mathrm{O}_{2}$ was measured via rotating ring-disk electrode (RRDE) in Fig. S3. The percentage of $\mathrm{H}_{2} \mathrm{O}_{2}$ of $\mathrm{N}, \mathrm{F}-\mathrm{MCF}-\mathrm{A}$ is below $10 \%$, and $n$ is about 3.75 in the potential range from 0 to $0.8 \mathrm{~V}$ versus RHE (Fig. 4g) in $0.1 \mathrm{M} \mathrm{KOH}$, which indicates the low peroxide formation and promising ORR activity. The poisoning experiment with $\mathrm{CN}^{-}$, which can strongly bond to active metal sites, was performed to identify the active sites of the prepared catalysts [38]. As shown in Fig. 4h, although the limiting current density drops a little, the onset potential and half-wave potential of N, F-MCFs-A almost unchanged with and without $\mathrm{CN}^{-}$in $0.1 \mathrm{M} \mathrm{KOH}$. That means the catalytic active sites in N, F-MCFs-A are primarily derived from the F-doped and $\mathrm{N}$-doped carbon sites rather than from other metallic coordination sites.

The ORR electrocatalytic performance of N, F-MCFs was also tested in acid media. In Fig. 5a, CV measurements in $\mathrm{O}_{2}$-saturated $0.5 \mathrm{M} \mathrm{H}_{2} \mathrm{SO}_{4}$ show that the curve peak of $\mathrm{N}$, F-MCFs-A is at $0.649 \mathrm{~V}$ (vs. RHE), at which the potential is negative as compared to that of commercial $\mathrm{Pt} / \mathrm{C}$ (0.748 V vs. RHE). Similarly, LSV measurements (Fig. 5b) in $\mathrm{O}_{2}$-saturated $0.5 \mathrm{M} \mathrm{H}_{2} \mathrm{SO}_{4}$ with various rotating speeds from 400 to $2000 \mathrm{rpm}$ and a scan rate of $10 \mathrm{mV} \mathrm{s}^{-1}$ also exhibit slightly poor onset potential (0.635 V vs. RHE) and half-wave potential ( $0.257 \mathrm{~V}$ vs. RHE). However, the electron transfer number is calculated to be approximately 4.0 for $\mathrm{N}$, F-MCFs in $0.5 \mathrm{M} \mathrm{H}_{2} \mathrm{SO}_{4}$ from the corresponding $\mathrm{K}-\mathrm{L}$ plots (Fig. 5c), which indicates that N, F-MCFs have a probable application prospect for ORR electrocatalytic activity in acid media. (a)

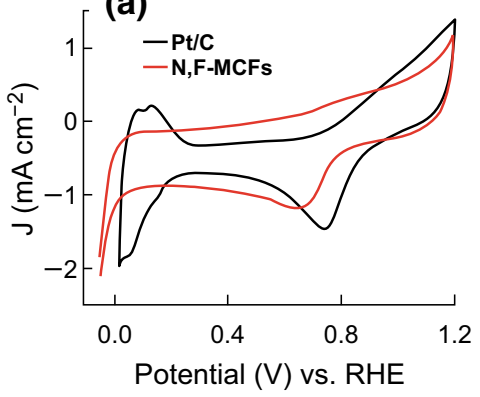

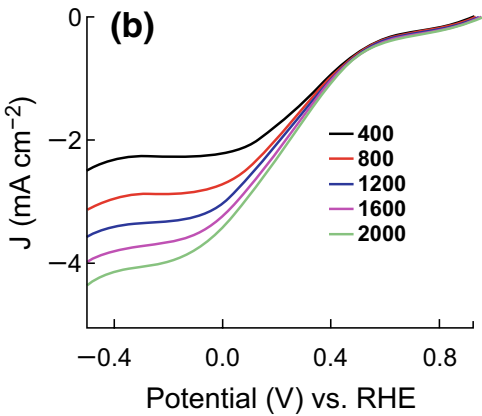

(c)

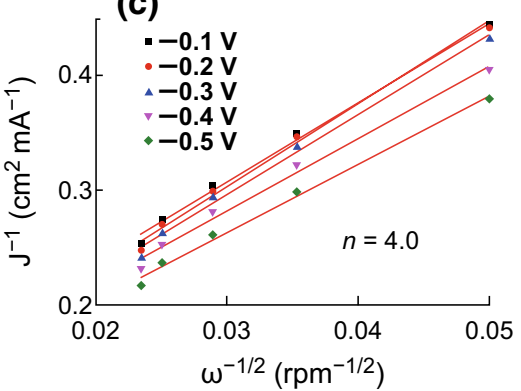

Fig. 5 a CV curves of N, F-MCFs-A and $\mathrm{Pt} / \mathrm{C} 20 \%$ in $\mathrm{O}_{2}$-saturated $0.5 \mathrm{M} \mathrm{H}_{2} \mathrm{SO}_{4}$ with a scan rate of $10 \mathrm{mV} \mathrm{s}^{-1}$. b LSV curves and $\mathbf{c} \mathrm{K}-\mathrm{L}$ plots of $\mathrm{N}, \mathrm{F}-\mathrm{MCF}$-A in $\mathrm{O}_{2}$-saturated $0.5 \mathrm{M} \mathrm{H}_{2} \mathrm{SO}_{4}$ with a scan rate of $10 \mathrm{mV} \mathrm{s}^{-1}$

(a)

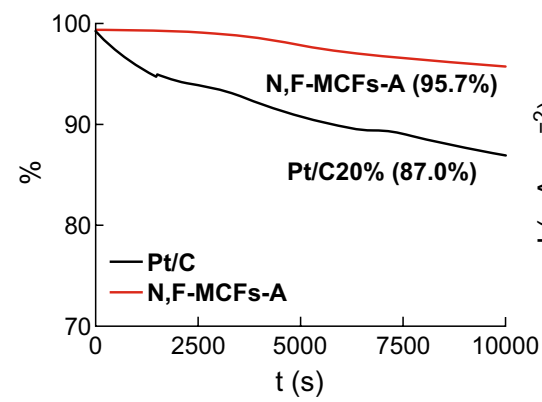

(b)

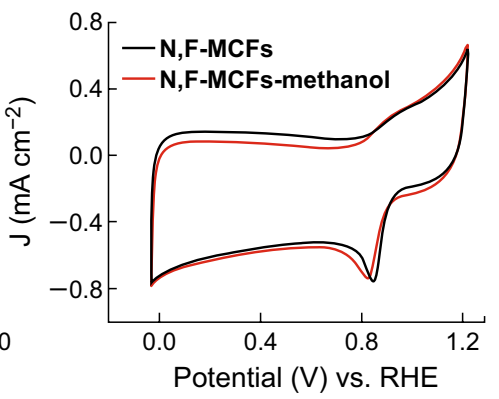

(c)

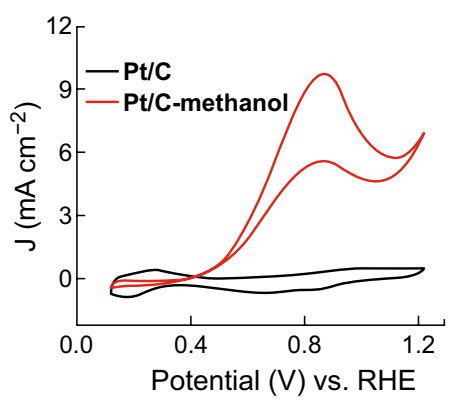

Fig. 6 a Current-time $(i-t)$ chronoamperometric response of N, F-MCFs-A and Pt/C $20 \%$ in $\mathrm{O}_{2}$-saturated $0.1 \mathrm{M} \mathrm{KOH}$ at a rotating rate of $1600 \mathrm{rpm}$ for $10,000 \mathrm{~s}$. b CV curves of N, F-MCFs-A and c Pt/C $20 \%$ with and without $3 \mathrm{wt} \% \mathrm{CH}_{3} \mathrm{OH}$ in $0.1 \mathrm{M} \mathrm{KOH}$ 
Furthermore, the durability and tolerance to methanol oxidation of N, F-MCFs-A in $0.1 \mathrm{M} \mathrm{KOH}$ were also investigated. The current-time $(i-t)$ chronoamperometric responses of N, F-MCFs-A and commercial Pt/C were measured under $0.6 \mathrm{~V}$ (vs. RHE) in $\mathrm{O}_{2}$-saturated $0.1 \mathrm{M} \mathrm{KOH}$ at a rotating rate of $1600 \mathrm{rpm}$ for 10,000 s. As shown in Fig. 6a, the relative current density of N, F-MCFs-A decreased more slowly than commercial $\mathrm{Pt} / \mathrm{C}$ with continuous reaction. It retained a superior higher relative current of $95.7 \%$, while commercial $\mathrm{Pt} / \mathrm{C}$ only retained $87.0 \%$. The $\mathrm{CV}$ curves of methanol tolerance test (Fig. 6b, c) showed that methanol has almost no effect on N, F-MCFs-A; however, a typical methanol oxidation/reduction curve can be observed for Pt/C. Thus, N, F-MCFs-A exhibit not only higher stability but also better methanol resistance than commercial $\mathrm{Pt} / \mathrm{C}$, which indicates that N, F-MCFs-A can be a practical metal-free ORR catalyst in fuel cells.

\section{Conclusions}

In summary, we demonstrated a facile method to synthesize $\mathrm{N}, \mathrm{F}-\mathrm{MCF}$ electrocatalysts via electrospinning PAN/PVDF/ PVP tricomponent polymers followed by the hydrothermal process and thermal carbonization. N, F-MCFs exhibited distinguished electrocatalytic activity for ORR in alkaline media, including higher onset potential (0.94 V vs. RHE), half-wave potential ( $0.81 \mathrm{~V}$ vs. RHE), and electron transfer number (4.0) because of their unique nanofiber structure with microporous pore walls and synergistic effect of high doped $\mathrm{F}$ and $\mathrm{N}$ content. In acidic media, the N, F-MCFs also exhibited a four-electron transfer pathway for ORR. In addition, the N, F-MCFs showed outstanding tolerance to methanol and superior stability (95.7\%) compared to commercial $\mathrm{Pt} / \mathrm{C}$ catalysts. As a result of all the superior electrocatalytic performance, this work provides an efficient pathway of in situ synthesis of N, F-MCFs as a highly active metal-free ORR electrocatalyst in the further application of fuel cells.

Acknowledgements We gratefully acknowledge funding for this work provided by the National Nature Science Foundation of China (51573090), National Key R\&D Program of China (2016YFB0302000) and Open Foundation from State Key Laboratory of Fluorinated Functional Membrane Material.

Open Access This article is distributed under the terms of the Creative Commons Attribution 4.0 International License (http:// creativecommons.org/licenses/by/4.0/), which permits unrestricted use, distribution, and reproduction in any medium, provided you give appropriate credit to the original author(s) and the source, provide a link to the Creative Commons license, and indicate if changes were made.

Electronic supplementary material The online version of this article (https://doi.org/10.1007/s40820-019-0240-x) contains supplementary material, which is available to authorized users.

\section{References}

1. F.T. Wagner, B. Lakshmanan, M.F. Mathias, Electrochemistry and the future of the automobile. J. Phys. Chem. Lett. 1(14), 2204-2219 (2010). https://doi.org/10.1021/jz100553m

2. M. Shao, Q. Chang, J.P. Dodelet, R. Chenitz, Recent advances in electrocatalysts for oxygen reduction reaction. Chem. Rev. 116(6), 3594 (2016). https://doi.org/10.1021/acs.chemr ev.5b00462

3. P.C.K. Vesborg, T.F. Jaramillo, Addressing the terawatt challenge: scalability in the supply of chemical elements for renewable energy. ChemInform 43(50), 7933-7947 (2015). https://doi.org/10.1039/C2RA20839C

4. M.K. Debe, Electrocatalyst approaches and challenges for automotive fuel cells. Nature 486(7401), 43-51 (2012). https ://doi.org/10.1038/nature11115

5. A. Rabis, P. Rodriguez, T.J. Schmidt, Electrocatalysis for polymer electrolyte fuel cells: recent achievements and future challenges. ACS Catal. 2(5), 864-890 (2012). https://doi. org/10.1021/cs3000864

6. T. Binninger, E. Fabbri, R. Kötz, T.J. Schmidt, Determination of the electrochemically active surface area of metal-oxide supported platinum catalyst. J. Electrochem. Soc. 161(3), H121-H128 (2014). https://doi.org/10.1149/2.055403jes

7. D.D.F. Vliet, D.C. Wang, D. Li, A.P. Paulikas, D.J. Greeley et al., Unique electrochemical adsorption properties of pt-skin surfaces \& dagger. Angew. Chem. Int. Ed. 13(51), 3139-3142 (2012). https://doi.org/10.1002/anie.201107668

8. M. Shao, A. Peles, K. Shoemaker, Electrocatalysis on platinum nanoparticles: particle size effect on oxygen reduction reaction activity. Nano Lett. 11(9), 3714-3719 (2011). https://doi. org/10.1021/nl2017459

9. M. Li, Z. Zhao, T. Cheng, A. Fortunelli, C.Y. Chen et al., Ultrafine jagged platinum nanowires enable ultrahigh mass activity for the oxygen reduction reaction. Science 354(6318), 1414-1419 (2016). https://doi.org/10.1126/science.aaf9050

10. N. Jung, D.Y. Chung, J. Ryu, S.J. Yoo, Y.-E. Sung, Pt-based nanoarchitecture and catalyst design for fuel cell applications. Nano Today 9(4), 433-456 (2014). https://doi.org/10.1016/j. nantod.2014.06.006

11. B. Wu, N. Zheng, Surface and interface control of noble metal nanocrystals for catalytic and electrocatalytic applications. Nano Today 8(2), 168-197 (2013). https://doi.org/10.1016/j. nantod.2013.02.006 
12. L. Dai, Y. Xue, L. Qu, H.J. Choi, J.B. Baek, Metal-free catalysts for oxygen reduction reaction. Chem. Rev. 115(11), 4823-4892 (2015). https://doi.org/10.1021/cr5003563

13. R. Othman, A.L. Dicks, Z. Zhu, Non precious metal catalysts for the pem fuel cell cathode. Int. J. Hydrog. Energy 37(1), 357-372 (2012). https://doi.org/10.1016/j.ijhyd ene.2011.08.095

14. D. Guo, R. Shibuya, C. Akiba, S. Saji, T. Kondo, J. Nakamura, Active sites of nitrogen-doped carbon materials for oxygen reduction reaction clarified using model catalysts. Science 351(6271), 361-365 (2016). https://doi.org/10.1126/scien ce.aad0832

15. S. Li, X. Yuan, H. Kong, J. Xu, Z. Ma, Fe-PPy-TsOH/C as cathode catalyst for proton exchange membrane fuel cells. J. Inorg. Mater. 32(4), 393-399 (2017). https://doi.org/10.15541/jim20 160399

16. J. Liu, B.V. Cunning, T. Daio, A. Mufundirwa, K. Sasaki, S.M. Lyth, Nitrogen-doped carbon foam as a highly durable metalfree electrocatalyst for the oxygen reduction reaction in alkaline solution. Electrochim. Acta 220, 554-561 (2016). https://doi. org/10.1016/j.electacta.2016.10.090

17. D. Gu, Y. Zhou, R. Ma, F. Wang, Q. Liu, J. Wang, Facile synthesis of N-doped graphene-like carbon nanoflakes as efficient and stable electrocatalysts for the oxygen reduction reaction. Nano-Micro Lett. 10(2), 29 (2018). https://doi.org/10.1007/ s40820-017-0181-1

18. R. Xing, T. Zhou, Y. Zhou, R. Ma, Q. Liu, J. Luo, J. Wang, Creation of triple hierarchical micro-meso-macroporous N-doped carbon shells with hollow cores toward the electrocatalytic oxygen reduction reaction. Nano-Micro Lett. 10(1), 3 (2018). https ://doi.org/10.1007/s40820-017-0157-1

19. L. Yang, S. Jiang, Y. Zhao, L. Zhu, S. Chen et al., Boron-doped carbon nanotubes as metal-free electrocatalysts for the oxygen reduction reaction. Angew. Chem. Int. Ed. 50(31), 7132-7135 (2011). https://doi.org/10.1002/anie.201101287

20. E. Pourazadi, E. Haque, S.N. Faisal, A.T. Harris, Identification of electrocatalytic oxygen reduction (ORR) activity of boron in graphene oxide; incorporated as a charge-adsorbate and/or substitutional p-type dopant. Mater. Chem. Phys. 207, 380-388 (2018). https://doi.org/10.1016/j.matchemphys.2017.12.090

21. L. Zhang, Y. Wang, K. Wan, J. Piao, Z. Liang, Effective sulfurdoping in carbon by high-temperature molten salt bath and its electrocatalysis for oxygen reduction reaction. Electrochem. Commun. 86, 53-56 (2018). https://doi.org/10.1016/j.eleco m.2017.11.015

22. J. Liang, Y. Jiao, M. Jaroniec, S.Z. Qiao, Sulfur and nitrogen dual-doped mesoporous graphene electrocatalyst for oxygen reduction with synergistically enhanced performance. Angew. Chem. Int. Ed. 124(46), 11664-11668 (2012). https://doi. org/10.1002/ange.201206720

23. H. Huang, X. Feng, C. Du, W. Song, High-quality phosphorusdoped $\mathrm{MOS}_{2}$ ultrathin nanosheets with amenable ORR catalytic activity. Chem. Commun. 51(37), 7903-7906 (2015). https://doi. org/10.1039/C5CC01841B

24. C. Zhang, N. Mahmood, H. Yin, F. Liu, Y. Hou, Synthesis of phosphorus-doped graphene and its multifunctional applications for oxygen reduction reaction and lithium ion batteries. Adv. Mater. 25(35), 4932-4937 (2013). https://doi.org/10.1002/ adma.201301870

25. X. Sun, Y. Zhang, P. Song, J. Pan, L. Zhuang, W. Xu, W. Xing, Fluorine-doped carbon blacks: highly efficient metal-free electrocatalysts for oxygen reduction reaction. ACS Catal. 3(8), 1726-1729 (2013). https://doi.org/10.1021/cs400374k

26. H. Wang, A. Kong, Mesoporous fluorine-doped carbon as efficient cathode material for oxygen reduction reaction. Mater. Lett. 136, 384-387 (2014). https://doi.org/10.1016/j.matle t.2014.08.081

27. S.G. Peera, A.K. Sahu, A. Arunchander, S.D. Bhat, J. Karthikeyan, P. Murugan, Nitrogen and fluorine co-doped graphite nanofibers as high durable oxygen reduction catalyst in acidic media for polymer electrolyte fuel cells. Carbon 93, 130-142 (2015). https://doi.org/10.1016/j.carbon.2015.05.002

28. X. Yue, C. He, C. Zhong, Y. Chen, S.P. Jiang, P.K. Shen, Fluorine-doped and partially oxidized tantalum carbides as nonprecious metal electrocatalysts for methanol oxidation reaction in acidic media. Adv. Mater. 28(11), 2163-2169 (2016). https://doi. org/10.1002/adma.201504401

29. K. Kakaei, A. Balavandi, Hierarchically porous fluorine-doped graphene nanosheets as efficient metal-free electrocatalyst for oxygen reduction in gas diffusion electrode. J. Colloid Interface Sci. 490, 819-824 (2017). https://doi.org/10.1016/j. jcis.2016.12.011

30. G. Panomsuwan, N. Saito, T. Ishizaki, Simple one-step synthesis of fluorine-doped carbon nanoparticles as potential alternative metal-free electrocatalysts for oxygen reduction reaction. J. Mater. Chem. A 3(18), 9972-9981 (2015). https://doi. org/10.1039/C5TA00244C

31. H. Zhou, Y. Peng, H.B. Wu, F. Sun, H. Yu, F. Liu, Q. Xu, Y. Lu, Fluorine-rich nanoporous carbon with enhanced surface affinity in organic electrolyte for high-performance supercapacitors. Nano Energy 21, 80-89 (2016). https://doi.org/10.1016/j.nanoe n.2015.12.016

32. H. Wang, J. Ding, J. Zhang, C. Wang, W. Yang, H. Ren, A. Kong, Fluorine and nitrogen co-doped ordered mesoporous carbon as a metal-free electrocatalyst for oxygen reduction reaction. RSC Adv. 6(83), 79928-79933 (2016). https://doi.org/10.1039/ C6RA14748H

33. S. Zhang, Y. Cai, H. He, Y. Zhang, R. Liu et al., Heteroatom doped graphdiyne as efficient metal-free electrocatalyst for oxygen reduction reaction in alkaline medium. J. Mater. Chem. A 4(13), 4738-4744 (2016). https://doi.org/10.1039/C5TA10579J

34. Y. Lv, L. Yang, D. Cao, Nitrogen and fluorine-codoped porous carbons as efficient metal-free electrocatalysts for oxygen reduction reaction in fuel cells. ACS Appl. Mater. Interfaces 9(38), 32859-32867 (2017). https://doi.org/10.1021/acsami.7b11371

35. K. Kakaei, A. Balavandi, Synthesis of halogen-doped reduced graphene oxide nanosheets as highly efficient metal-free electrocatalyst for oxygen reduction reaction. J. Colloid Interface Sci. 463, 46-54 (2016). https://doi.org/10.1016/j.jcis.2015.10.030

36. Y. Huang, Y.E. Miao, S. Ji, W.W. Tjiu, T. Liu, Electrospun carbon nanofibers decorated with Ag-Pt bimetallic nanoparticles 
for selective detection of dopamine. ACS Appl. Mater. Interfaces 6(15), 12449-12456 (2014). https://doi.org/10.1021/am502344p

37. K. Mayrhofer, G. Wiberg, M. Arenz, Impact of glass corrosion on the electrocatalysis on Pt electrodes in alkaline electrolyte. J. Electrochem. Soc. 155(1), 1-5 (2008). https://doi. org/10.1149/1.2800752
38. W.C. Min, H.C. Chang, S.Y. Lee, S.I. Woo, Dimensionalitydependent oxygen reduction activity on doped graphene: is graphene a promising substrate for electrocatalysis? Nano Energy 11, 526-532 (2015). https://doi.org/10.1016/j.nanoe n.2014.11.002 